\section{A influência da AIDS no processo de desenvolvimento organizacional das organizações não-governamentais: um estudo de caso sobre a Casa de Assistência Filadélfia}

\author{
The impact of AIDS on the organizational \\ development of nongovernmental organizations: a \\ case study on Casa de Assistência Filadélfia
}

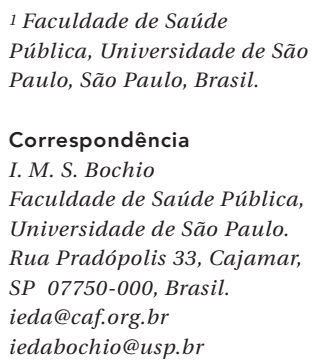

\begin{abstract}
AIDS has been a unique event due not only to its devastating effects, but also to the ways in which it has stimulated solidarity and mobilization of society in the defense of the rights of persons living with HIVIAIDS and their families, friends, and contacts. Beginning as initiatives to ensure dignity in death, AIDS NGOs have undergone structural changes to respond to the demands raised by the epidemic. The current study describes the history of the Brazilian AIDS NGO "Casa de Assistência Filadélfia" in relation to the evolution of the AIDS epidemic, highlighting the issue of organizational development. A qualitative case study methodology was used, and the data were collected from document analysis and semi-structured interviews with key informants identified by the organization. Data analysis was based on the theoretical premises of organizational development and shows how the organization made the transition from the pioneering phase marked by improvisation and expanded to a phase of regulation until reaching flexibility and innovation by diversifying its projects. The study highlights the importance of organizational development as an essential element in building healthy, agile organizations in the response to their demands.
\end{abstract}

Acquired Immunodeficiency Syndrome; NonGovernmental Organizations; Organizational Case Studies
Ieda Maria Siebra Bochio 1

Paulo Antonio de Carvalho Fortes 1

\section{Introdução}

O surgimento da AIDS como epidemia e posteriormente como pandemia foi um evento marcante tanto por sua capacidade devastadora, quanto pela forma como estimulou a solidariedade e a mobilização da sociedade na defesa dos direitos de pessoas vivendo e convivendo com HIV/AIDS 1,2,3. Essa participação gerou multiformes respostas e promoveu mudanças importantes, que se expressaram no comportamento das pessoas, no perfil e na organização dos serviços prestados, assim como na construção de políticas públicas, o que foi, segundo Galvão 3 (p. 341), um ganho da AIDS: "Se por um lado a AIDS provocou os mais arbitrários julgamentos de valor, por outro lado possibilitou as mais diversas respostas de pessoas, entidades, grupos e organizações da sociedade civil, que se mobilizaram em defesa dos direitos das pessoas afetadas pelo HIVIAIDS".

A vivência com o vírus HIV tornou notórias as necessidades que se davam em planos subjetivos gerando uma nova compreensão sobre vulnerabilidade 4,5 , contribuindo para a formação de ambientes que oportunizaram identificações, trocas e construções coletivas envolvendo portadores do vírus, familiares e simpatizantes da causa. A atuação solidária, no entanto, transcendeu para uma apropriação dos espaços de discussão e decisão ganhando lugar na formulação de políticas públicas 1,3,6. 
As iniciativas, que surgiram também como parte da resposta reativa dos movimentos sociais engajados na reforma sanitária foram assim consolidando-se como organizações e incorporando-se dentro do Terceiro Setor 7,8,9, aqui compreendido pelo "conjunto de organizações privadas sem fins lucrativos, de interesse social, fundadas e geridas por cidadãos com a finalidade de promover os interesses da cidadania em vários campos da atuação social" 7 (p. 235). A participação social acontece assim por intermédio da organização não-governamental (ONG) enquanto ator social, num misto de ação solidária e ativismo político.

As ONGs, de forma geral, mas em especial as ONGs/AIDS, foram alavancadas também pelo interesse internacional, num estímulo que não se deu apenas no plano das idéias, mas por meio do financiamento de iniciativas, nas relações entre entidades internacionais e governos e, destes para com as organizações locais redesenhando o papel desses atores no cenário social. Cabe destacar o papel do Banco Mundial a partir de 1994 nos acordos para financiamento de projetos que deram base para a criação do Programa Nacional de DST/AIDS, no qual o incentivo à participação das ONGs, seguindo a lógica da maior participação da sociedade para o alcance de metas, fortaleceu o ativismo político e a presença destas nos espaços de decisão 10,11,12.

Essa relação organizacional, assim como a necessidade de autopreservação forçou mudanças estruturais para a maioria das ONGs. Houve uma busca pela profissionalização nas atividades e uma procura por ferramentas de gestão, em sua maioria importadas de outras áreas de administração 13,14, uma reinvenção que permitiu que respondessem com maior propriedade às contingências da epidemia da AIDS, caracterizada pela complexidade das constantes mudanças no perfil epidemiológico e pelos decorrentes desdobramentos sócio-políticos.

Mudança é uma palavra representativa ainda hoje no contexto da epidemia (ou pandemia) da AIDS, que em sua forma de transmissão iniciouse nos então chamados "grupos de risco", feminilizou-se, atingiu as crianças, saiu das rotas das grandes capitais e pauperizou-se $4,5,15,16,17$ numa socialização perversa da doença.

Com o avanço na terapia medicamentosa e a estruturação do atendimento a AIDS passou a ser encarada como uma doença crônica. Entretanto, sua disseminação, grandemente relacionada às subjetividades da expressão da sexualidade, ainda ocorre como um elemento promotor de mudança. Dentro desse quadro, a gestão das ONGs/AIDS não poderia acontecer desconsiderando essa característica de "mutante" que o HIV atribuiu também às organizações. De iniciativas assistenciais que surgiram para dar dignidade na morte, as ONGs/AIDS passaram a atuar na defesa de direitos, influenciando comportamentos e fomentando mudanças políticas, que como o próprio HIV, modificaram-se e tornaram-se resistentes.

O Desenvolvimento Organizacional, cuja palavra chave é Mudança, é uma teoria da administração que surgiu nos anos 60, período marcado por profundas transformações na sociedade e que indicou, como que profeticamente, como as inovações e a resposta organizacional fariam parte da dinâmica do novo milênio 18 .

O presente estudo objetiva descrever a trajetória de uma ONG/AIDS com relação à evolução da epidemia de AIDS, identificando mudanças organizacionais que se caracterizem como indicadores de desenvolvimento organizacional, tendo como referencial teórico o Desenvolvimento Organizacional. Num momento em que novas parcerias se estabelecem entre o Estado e diferentes atores sociais 19 para a concretização de políticas públicas de saúde, a necessidade de pesquisar o trabalho das ONGs/AIDS fica ainda mais evidenciada pelas mudanças que elas têm fomentado em direção aos demais setores que com elas interagem na construção do cenário sócio-político.

\section{Métodos}

Realizou-se uma pesquisa qualitativa com o estudo de caso único 20 para verificar a evolução da organização Casa de Assistência Filadélfia (CAF), caracterizada por sua estrutura de pessoa jurídica como ONG, tendo existência jurídica superior a dez anos. A organização é sediada na Cidade de São Paulo e atua dentro da Região Metropolitana de São Paulo no apoio a crianças e adolescentes e seus familiares vivendo e convivendo com HIV/ AIDS, e em situação de vulnerabilidade social.

O estudo compreendeu o período de 1995, quando a organização passou a existir como pessoa jurídica, até o ano de 2005. Para a análise documental foram considerados todos os documentos oficiais gerados pela organização ou pertencentes ao seu acervo e referentes à sua formação, tais como: estatutos, atas, levantamentos históricos, regimentos internos, folder promocional, matérias publicadas em jornais, cartas de apresentação e de solicitações a parceiros, stakeholders etc.

Foram feitas também entrevistas parcialmente estruturadas com informantes-chave sugeridos pela ONG, compondo o quadro das diferentes representatividades que fizeram parte da formação histórica e da continuidade da 
organização até aquele momento, a saber: três participantes dos projetos (duas mulheres e um homem, uma mulher com o segundo grau incompleto e os demais com o primeiro grau incompleto, todos na faixa etária entre 30 e 45 anos de idade, com renda média inferior a três salários mínimos. Levou-se em consideração serem soropositivos para HIV e participantes assíduos das atividades proporcionadas pela organização); duas lideranças (deu-se preferência para as que tivessem participado de mais de um mandato de diretoria: ambas mulheres, na faixa etária entre 40 e 50 anos, com o segundo grau completo, renda superior a cinco salários mínimos); dois voluntários (foram consideradas pessoas com uma atividade sistemática e não remunerada dentro da organização: uma mulher, na faixa etária entre 20 e 30 anos, um homem com idade entre 40 e 50 anos, ambos com o terceiro grau completo e renda superior a cinco salários mínimos); dois parceiros (foi considerada a designação de parceiros feita no estatuto, ou seja, organizações que contribuem financeira e tecnicamente de forma sistemática para os projetos ou para a organização, os entrevistados são representantes dos parceiros para a ONG: um homem com o terceiro grau completo, na faixa etária entre 30 e 45 anos, e uma mulher com o terceiro grau completo e idade entre 30 e 40 anos, não foi mencionada a renda); dois funcionários (foram considerados aqueles com tempo superior a dois anos de trabalho dentro da organização: uma mulher na faixa etária entre $40 \mathrm{e}$ 50 anos, com o segundo grau completo e renda entre 3 e 5 salários mínimos, um homem com o terceiro grau completo, idade entre 30 e 40 anos e renda superior a cinco salários mínimos).

As entrevistas foram realizadas individualmente e gravadas em meio magnético pela primeira autora. O trabalho foi aprovado pelo Comitê de Ética em Pesquisa da Faculdade de Saúde Pública da Universidade de São Paulo, em 29 de abril de 2005.

Para a leitura e pesquisa de documentos da organização, bem como para a entrevista com informantes-chave, foi solicitado a então presidente da organização um consentimento por meio de um Termo de Autorização, o qual resguarda o uso das informações. Todos os sujeitos da pesquisa foram esclarecidos por intermédio de um Termo de Consentimento Livre e Esclarecido conforme requisitos da Resolução o no. 196/96 do Conselho Nacional de Saúde 21 .

A análise dos dados foi feita baseando-se nas proposições teóricas de Desenvolvimento Organizacional 20 em que o desenvolvimento organizacional indica mudanças de fase que vão desde a fase pioneira (improvisação), fase de expansão (oportunidades), fase de regulamentação (definição de processos de trabalho), fase de burocratização (sistema de regras), até a fase de flexibilização (capacidade inovadora). A mudança organizacional é compreendida como adaptabilidade, sendo elemento gerador de inovação que acontece em três áreas: estrutura, tecnologia e comportamento 22 .

\section{Resultados}

A reconstrução histórica possibilitou a identificação de uma seqüência de mudanças organizacionais, cada uma delas indicando como a ONG/ AIDS CAF adaptou-se às demandas da epidemia. Passou de uma ação empreendedora originada na urgência 23 para uma organização promotora de saúde com capacidade de estimular a participação social por meio da adesão à causa da luta pela erradicação da AIDS. As mudanças organizacionais que acompanham simultaneamente a história da epidemia indicam a capacidade de resposta organizacional e a busca pela inovação como forma de autopreservação dentro do cenário sócio-político e organizacional definido nos seguintes momentos: (i) o surgimento da CAF como ONG; (ii) a CAF estende sua ação para a família; (iii) maior expectativa de vida: a crise da CAF de existir como ONG/AIDS; (iv) o fomento internacional e a profissionalização da ONG; e (v) da assistência ao protagonismo: o desafio da autonomia.

\section{O surgimento da CAF como organização não governamental}

A CAF começou no final dos anos 80 com o trabalho da fundadora, uma cristã de tradição presbiteriana, em cujos valores de fé estavam bastante impregnadas a prática de servir ao próximo.

Seu contato com a AIDS se deu através da contaminação do único filho. Como muitas mães nessa época, ela precisou assumir as responsabilidades do cuidado, uma decisão de continuar ou não ao lado dele após a constatação da homossexualidade e da doença. Esse foi um momento da epidemia em que muitos jovens morriam completamente sozinhos e amedrontados em suas casas ou nos quartos de hospital, e onde as pessoas adoecidas eram de forma geral tratadas sem o menor respeito 24 . Essa característica relacional estimulada dentro da epidemia fez nascer o termo "pessoas vivendo e convivendo com a AIDS" 1, evidenciando o fato de que, a doença não pertencia somente aos portadores do vírus, e sim, interligava a todos na convivência diária. A AIDS fomentou a reflexão não apenas 
sobre os comportamentos, mas sobre os valores que os motivam.

O trabalho de assistir os doentes era feito de maneira caseira no próprio apartamento da fundadora e com recursos próprios ou doados por amigos. Incluía o apoio emocional, a distribuição de alimentos e de remédios. Ela fazia arranjos e interlocuções para abrigar jovens que eram expulsos de suas casas, prestando cuidado mais direto para aqueles que se encontravam acamados, um contato com os doentes em seu estado mais frágil que desafiava os temores da época. A fundadora se tornava a mãe para a maioria dos moribundos que atendia, ao mesmo tempo em que servia de mãe para as próprias mães deles, que se tornavam verdadeiramente "as primeiras órfãs da AIDS”, um termo aqui emprestado uma vez que não há uma terminologia própria para os pais que perdem seus filhos.

A presença constante nos serviços de saúde, necessária por causa da doença e das constantes internações, descortinava a rotina destes serviços para os doentes e para os familiares e amigos que se solidarizavam. Isso possibilitava uma apropriação de novas práticas, marcando o período como um momento fértil no surgimento de terapias alternativas 24 . As histórias de contaminação repetiam-se com diferentes roupagens e a epidemia fomentava o surgimento de diferentes empreendedores sociais, como a própria fundadora da CAF; muitos dos quais se tornaram ícones na luta contra a AIDS, compartilhando os poucos recursos e a tarefa de apoiar os doentes numa prática da solidariedade que de alguma forma identifica as organizações que compõem o Terceiro Setor 2,9,25,26.

\section{A CAF estende sua ação para a família}

Se num primeiro momento a fundadora se viu compelida a atender os doentes, abandonados por seus familiares, novas realidades como a das mulheres que se descobriam gestantes e soropositivas e de seus filhos, herdeiros do vírus, exigiram outra abordagem.

Com o apoio da liderança da igreja que freqüentava e com o argumento dos valores de sua fé, a iniciativa de atendimento aos doentes se estruturou na conformação de ONG, um formato bastante próprio do modelo sul-americano do Terceiro Setor 26,27. O atendimento às pessoas era feito diariamente na sede alugada, ou por meio das visitas aos hospitais, centros de referência e também aos domicílios, numa modalidade de atendimento que se tornou o espaço das ONGs/ AIDS na assistência aos doentes.

Os profissionais do serviço social e psicologia de diversos hospitais encaminhavam ofi- cialmente pessoas à ONG, para que os doentes tivessem alguma assistência quando de sua alta hospitalar. A tarefa da informação e da prevenção da doença era compartilhada pelos profissionais da saúde e pelas pessoas da ONG, numa relação que marcava, mesmo que informalmente, o início de diferentes parcerias entre a ONG e outros setores da sociedade, e a necessidade da intersetorialidade 10.

$\mathrm{Na}$ ONG os participantes se encontravam uma vez por semana para as reuniões, um misto de culto e de reunião de auto-ajuda. Dentro de um contexto social de tanta rejeição, as "reuniões" traziam alento e os participantes as freqüentavam não apenas pela necessidade social das doações, mas porque "as reuniões" os ajudavam a enfrentar a sua própria realidade, as perdas, o afastamento e o preconceito, elementos que a ciência e a tecnologia sozinhas não dão conta de resolver 28,29 .

A ONG se consagrava como o espaço daquelas famílias, misto de refugio e gueto onde soropositivos, "ongueiros" e simpatizantes desenhavam uma participação social diferenciada do que se conhecia nos movimentos populares. Era uma proposta humanizadora que se contrapunha ao preconceito e que caminhava para uma leitura da realidade de dentro para fora, o que sem dúvida contribuiu para o processo de desenvolvimento e de transformação estrutural da sociedade, confirmando sua função como $\mathrm{ONG}^{30}$.

\section{Maior expectativa de vida: a crise da CAF de existir como ONG/AIDS}

O desenvolvimento de novos medicamentos indicou outros rumos para a epidemia. Deixou-se de "assistir para a morte" e o discurso se direcionou para a "maior qualidade de vida", o que levou, tanto os portadores como as ONGs, a reaprender o sentido do que consideravam "normalidade".

O clima de urgência que existia no atendimento passou gradualmente a ser substituído por um clima de apoio e de uma solidariedade menos dramática. Se as pessoas se aglomeravam antes em busca da ajuda, com a estabilidade do tratamento a ONG passava a ser procurada numa modalidade diferente daquela dos primeiros tempos da epidemia. Os próprios serviços de saúde ofereciam um apoio muito similar ao da ONG, promovendo encontros, doando alimentos e organizando festas. Assim, aquilo que antes era um grande diferencial, foi sofrendo o risco da "competitividade".

Os usuários dos serviços de saúde eram também freqüentadores de ONGs como a CAF, onde ouviam com freqüência o "discurso do direito" e se valiam deste discurso para buscar o tratamen- 
to, o que reforçado pelos próprios profissionais da saúde envolvidos no atendimento ajudava a diferenciar os serviços voltados para pessoas vivendo e convivendo com HIV 24,31.

No caso da CAF a mudança na expressão da epidemia exigiu uma atuação que fosse menos assistencial, o que por um lado significava o aprendizado organizacional, por outro, contribuía para que em alguma medida o atendimento inicialmente prestado fosse considerado meramente como uma "ação caridosa", desvalorizando o papel que a assistência voluntária ocupou na história da AIDS.

As ONGs que no curso da epidemia haviam se dedicado a ações mais específicas no campo dos direitos humanos, muitas delas dirigidas por intelectuais e profissionais, eles próprios soropositivos e que tinham ligação com movimentos sociais e populares, passaram a ser compreendidas como "ONGs cidadãs" 32,33. Para alguém como a fundadora, que não exercia um papel de ativista propriamente dito e que havia se valido da causa para continuar a própria vida, deixar de atender ou ver a organização aos poucos definhando, significava perder-se como referencial. Era perder um filho novamente.

\section{O fomento internacional e a profissionalização da ONG}

A gestão da organização até 1999 era bastante informal e movida por boa vontade. Sem a participação da igreja que havia ajudado a fundar a ONG, os recursos vinham de doações esporádicas e não havia um grupo representativo de associados para quem reuniões administrativas e a prestação de contas fosse significante. Esse esvaziamento tanto de pessoas como de recursos exigiu que se buscassem novas alternativas. Nesse mesmo ano a CAF recebeu seu primeiro subsídio proveniente de uma agência de cooperação internacional, num período em que grandes investimentos governamentais e internacionais eram feitos nas ONGs AIDS 11. A compatibilidade de valores foi essencial para o início da nova parceria que começou a partir de um pedido elaborado de forma bastante simples numa carta manuscrita da fundadora dirigida à organização internacional.

A entrada do parceiro internacional, introduzindo as propostas por projetos e a formalização na prestação de contas, evidenciou a fragilidade da estrutura organizacional e a necessidade de gerenciamento e de sistematização de processos. A primeira consultoria, realizada com o apoio do parceiro, indicava o início de um período de mudanças estruturais em que o consultor figurava como um mediador entre os parceiros, traduzin- do nos relatórios as necessidades e expectativas de cada lado. Para a então liderança da ONG, acolher as orientações da consultoria representava a sobrevivência da organização, pois isto garantia de certa forma a continuidade do subsídio financeiro, mas também, porque no panorama apresentado pela epidemia adequar-se como organização era um imperativo para continuar operando.

Deu-se então a contratação de um profissional da saúde com experiência em administração para atuar na gestão da instituição, seguindo um processo formal de escolha que contrariava o imaginário sobre a "informalidade das ONGs" e que confirma uma tendência da administração das ONGs de ser exercida por diferentes profissionais numa lógica diferenciada da administração pública ou empresarial 34 .

O trabalho da gestora foi estruturar a ONG agregando ao histórico humanitário da organização as experiências adquiridas nos relacionamentos com diferentes atores e organizações dentro e fora do país, numa overdose de informações que exigia rápida adaptação da equipe que se formava, mas também da liderança e das pessoas que participavam do projeto, promovendo um misto de instabilidade e entusiasmo organizacional.

Para formar uma nova liderança e dar continuidade à organização, numa modalidade diferente do que havia sido feito até aquele momento, ou seja, muito baseada na figura carismática da fundadora, a estratégia foi transferir a liderança da fundadora para a própria CAF, criando uma marca que pudesse ela mesma aliar o histórico do trabalho humanitário ao desafio da defesa de direitos e do protagonismo das pessoas vivendo e convivendo com HIV/AIDS, isto é, a maior consciência e poder de decisão sobre os rumos da própria vida 32 . A “CAF” expressa na logomarca de um rosto sorrindo que sugere um rosto feliz de criança era a junção do velho e do novo, ao mesmo tempo em que agregava os valores, neutralizava a ligação instantânea da instituição a uma só pessoa. A organização passava progressivamente a ser maior que os seus ícones.

\section{Da assistência ao protagonismo: o desafio} da autonomia

Definir a missão, tendo como foco as crianças e os adolescentes, ajudou a organização a dar um passo na direção de ações de maior impacto, aprender e estimular o protagonismo 32,35 pensando a criança e o adolescente fora do lugar comum - serem o "futuro da nação", até porque, para muitas delas, vivendo com HIV, o conceito de futuro poderia ser bastante discutível. 
Além disso, as crianças e adolescentes em sua grande maioria faziam parte de uma população vivendo em condições sociais de grande vulnerabilidade, em que ter o vírus era apenas mais um elemento dentro do contexto marcado pelas perdas, falta de acesso e exclusão social, problemas que se encontravam na base da pauperização da AIDS 4,5,16 e que indicavam que a doença já não pertencia só ao campo da saúde. Para responder às necessidades de atendimento dos casos e propor estratégias de prevenção seria necessária a interlocução de diferentes atores e saberes no sentido de promover ações de maior impacto e uma resposta mais expressiva por parte daqueles que eram os principais afetados, o que incluiria a definição de limitações e limites.

As pessoas vivendo com HIV devido à dinâmica da própria doença estavam afastadas da realidade do mercado de trabalho. Algumas mulheres nunca haviam exercido um trabalho remunerado e outras tinham se adaptado à realidade do subemprego ou até mesmo à condição de pedintes. Quando a ONG realizou o seu primeiro processo participativo envolvendo os beneficiários no planejamento estratégico, os resultados apontaram para a necessidade de manter as reuniões, pois estas consistiam o principal espaço de participação. Mas, os próprios beneficiários perceberam a necessidade de que fossem iniciadas atividades de inclusão que lhes possibilitassem "também ajudar e não apenas serem ajudados".

A utilização de uma metodologia participativa ${ }^{36}$ criou a ponte para que os participantes se descobrissem num novo papel dentro da organização. As reuniões passaram a dar espaço para a discussão não apenas das dificuldades relacionadas à doença, tais como o uso da medicação, mas também para a discussão de idéias e estratégias para o trabalho cooperativo. Temas como trabalho em equipe, liderança, sustentabilidade e gestão de recursos foram sendo acrescidos ao discurso do grupo dando início às primeiras oficinas para as famílias.

O propósito da ONG passou a ser o de desenvolver atividades ou produtos que pudessem trazer um retorno efetivo para as famílias participantes para que elas próprias pudessem cuidar de seus filhos, interrompendo o ciclo pobreza/ AIDS que já se alastrava para a terceira geração. A experiência que a ONG havia adquirido tanto na relação com os participantes quanto na relação com outras ONGs mostrava que havia um sério risco de iniciar atividades que fossem apenas ocupacionais e não propriamente de geração de renda, resultando em frustração. Além disso, o início de atividades com um maior grau de exigência imporia uma seleção natural entre os participantes e, conseqüentemente, promoveria uma diminuição do grupo, sendo assim uma decisão importante a ser tomada pela ONG.

Uma primeira oficina realizada pelas famílias para a confecção de enfeites de Natal com balas de goma não obteve retorno financeiro significante, mas possibilitou que tivessem sua primeira atividade em conjunto, percebendo a capacidade pessoal de realização e identificando as forças e as oportunidades do trabalho em grupo, acima de tudo verbalizando a crítica ao próprio trabalho e utilizando esta crítica para novas tentativas. Foi com base na metodologia participativa que as oficinas de patchwork e restauro de móveis tiveram o seu início. Sem o menor conhecimento anterior das técnicas necessárias, as famílias se dividiram entre essas duas atividades baseadas na confiança que haviam adquirido em sua primeira experiência como equipe.

A perspectiva protagonista abriu novas possibilidades de ação dentro da temática da AIDS e a ONG iniciou outros projetos. As experiências adquiridas no trabalho com as famílias haviam mostrado outras realidades que afetavam principalmente as crianças e adolescentes, tanto no adoecimento quanto na morte dos pais pela AIDS. A CAF então assumiu um abrigo para crianças e adolescentes vivendo com HIV/AIDS e passou a trabalhar com a temática do acolhimento e da inserção familiar. Posteriormente, iniciou um projeto de arte-educação para a prevenção de DST/AIDS e de abuso sexual infantil, tendo em vista que a contaminação pelo vírus extrapolava a relação transversal mãe/filho, e muito embora as informações não fossem precisas, a realidade da organização mostrava que muitas crianças e adolescentes estavam contraindo o vírus também em decorrência de violência sexual.

O início de novos projetos forçou um crescimento rápido da ONG e a diversificação da equipe, dentro de uma perspectiva trazida pela AIDS de se trabalhar com a multidisciplinaridade. Com isso outros associados e parceiros, dentre os quais as empresas e o governo foram sendo acrescidos, havendo tanto uma ampliação da adesão à causa da ONG como a entrada de novos interesses aos quais ela tinha de responder. Isso representou uma nova situação de mudança por colocar a organização em contato com demandas diferenciadas, com o risco de a ONG se tornar uma "terceirização" dos interesses dos parceiros e de enfraquecer seu papel como ator no desempenho do controle social. Esse novo panorama impôs a urgência de formalizar processos e criar políticas internas para estabelecer limites e dar continuidade à lógica de ser ONG.

Assim, o desafio de dar seguimento ao processo de desenvolvimento organizacional, garantindo a autonomia da ONG e fomentando o 
protagonismo das pessoas vivendo e convivendo com HIV, se deu numa crescente relação de confiança entre liderança, equipe de trabalho, voluntários, associados, parceiros e pessoas vivendo e convivendo com HIV/AIDS, construída ao longo da experiência organizacional da CAF que se fundia à história da AIDS.

\section{Discussão}

As ONGs/AIDS surgiram a princípio como iniciativas emergenciais num contexto de urgência para responder a uma necessidade, e de maneira despretensiosa foram se estruturando como organizações com propósitos de promoção social. Tenório ${ }^{30}$ (p. 11) chama atenção para o fato de que as ONGs atuam "visando contribuir para um processo de desenvolvimento que supõe transformações estruturais da sociedade", o que por definição é um propósito ambicioso, pois é mais do que introduzir um novo produto ou produzir uma necessidade, é interferir na cultura com base em novos sentidos e valores.

A teoria de Desenvolvimento Organizacional propõe que a mudança é uma necessidade dentro das organizações, sem mudanças há uma tendência de estagnação e morte. Com a evolução da AIDS algumas iniciativas deixaram de existir após o cumprimento de seu propósito inicial, enquanto outras buscaram no desenvolvimento organizacional maneiras de enfrentamento da realidade da AIDS, mas também, a autopreservação numa reinvenção do seu estado inicial. As constantes mudanças da epidemia forçaram um amadurecimento para as ONGs/AIDS, como a CAF, que precisou sobrepor-se ao período da informalidade inicial para então apresentar novas respostas traduzidas na prevenção, no acolhimento e na inserção social, na geração de renda, na defesa de direitos e na mobilização da sociedade, podendo estes serem considerados os seus principais produtos ou resultados. Uma organização é assim promotora de mudança, mas também, o resultado destas mudanças.

Pode-se concordar com Hernandez \& Caldas 37 quando afirmam que, muito embora haja resistência, os seres humanos desejam a mudança e que esta se sobrepõe ao sentimento de insegurança e de resistência proposta pela teoria de Desenvolvimento Organizacional. As constantes modificações do perfil da epidemia da AIDS caracterizaram as ONGs/AIDS como organizações muito ágeis em ler as contingências, apresentando uma resposta às mesmas, o que indica que a mudança não é necessariamente desejada, mas que na presença de um fator motivador, uma “causa motivadora”, os seus desconfortos são superados em favor deste ganho maior.

Os momentos observados no estudo, que acompanham também os principais momentos da epidemia da AIDS, mostram diferentes fases da ONG como os descritos na teoria de Desenvolvimento Organizacional. Uma fase pioneira em que se destaca o trabalho humanitário da fundadora e de seus voluntários e a formalização da organização; uma fase de expansão na qual a ONG inicia a parceria internacional, adota mecanismos de gestão e aumenta os relacionamentos, os projetos e parcerias; uma fase de regulamentação e burocratização, com a definição da missão, o desenho dos projetos, a participação dos beneficiários na tomada de decisão e a criação de políticas internas caminhando para a fase de flexibilização, em que a ONG realiza convênios e parcerias com outros setores ampliando a dimensão do trabalho e inovando a partir da relação intersetorial. As mudanças percebidas correspondem a um desenvolvimento que ocorre em três esferas: política, econômica e cultural.

A inovação que se dá tanto pela criação de novos projetos como pela adoção de metodologias que privilegiam a participação e a criatividade aparece como um resultado não planejado, pois o perfil inconstante da AIDS não possibilita antever com precisão as decisões a serem tomadas; as contingências é que encaminham as mudanças e as respostas organizacionais são fruto da capacidade desenvolvida pela ONG de reinventar-se.

Essa capacidade mutante diferencia as ONGs/AIDS de tantas outras organizações que atualmente interagem no contexto do atendimento de pessoas vivendo e convivendo com HIV/AIDS, vistas por alguns como uma invenção neoliberal para enfraquecer o Estado de bem-estar social 38 ou como entidades cidadãs por outros 2,6,32; o que chama a atenção sobre as ONGs/ AIDS é a maneira como foram, baseadas em seu histórico de atuação e valendo-se das oportunidades apresentadas, encontrando um perfil organizacional próprio que lhes garantiu um lugar legitimado interagindo com os demais atores, em alguns momentos aliando-se e em outros contrapondo-se, mas, sem dúvida, exercendo um papel propositor que acrescentou possibilidades de inovação no campo da saúde.

A conformação das ONGs como novos atores sociais ainda não foi absorvida totalmente dentro da cultura nacional, na qual são vistas com certo grau de desconfiança ou consideradas como espaços extremamente informais, muito embora, como no caso da CAF, muitas estejam estruturadas e sigam procedimentos organizacionais e administrativos muito semelhantes às organizações do primeiro ou segundo setor $39,40,41,42$. 
O que ocorre é que o surgimento dessas organizações exigiu e exigirá mudanças na conformação dos demais atores sociais para uma aprendizagem sobre novas dinâmicas e formas de interação, no sentido de promover mudanças sócio-políticas 10,40,43 tendo em vista o atendimento das necessidades que ainda estão presentes no cenário da AIDS.

\section{Conclusão}

As mudanças percebidas ao longo da história indicam uma organização em desenvolvimento reinventando-se frente às contingências e reafirmando-se perante o seu público. Pode-se com isso inferir que uma organização que se desenvolve é uma organização que aprende.

\section{Resumo}

A AIDS foi um evento marcante tanto por sua capacidade devastadora como pela forma como estimulou a solidariedade e a mobilização da sociedade na defesa dos direitos de pessoas vivendo e convivendo com HIVI AIDS. De iniciativas para dar dignidade na morte, as ONG/AIDS passaram por mudanças estruturais para responder às demandas da epidemia. Este estudo descreve a trajetória da ONG/AIDS Casa de Assistência Filadélfia com relação à evolução da epidemia de AIDS ressaltando o desenvolvimento organizacional. Utilizou-se uma metodologia qualitativa com estudo de caso, sendo os dados colhidos por meio de análise documental e entrevistas semi-estruturadas com informantes-chave referidos pela organização. A análise dos dados baseou-se nas proposições teóricas de desenvolvimento organizacional e mostra como a organização saiu da fase pioneira marcada pela improvisação, se expandiu, indo para uma fase de regulamentação até chegar à fase de flexibilização e inovação com a diversificação dos projetos. O estudo aponta para a importância do desenvolvimento organizacional como elemento essencial na formação de organizações saudáveis e ágeis na resposta às suas demandas.

Sindrome de Imunodeficiência Adquirida; Organizações Não Governamentais; Estudos de Casos Organizacionais
Como organizações, as ONGs, e dentre estas as ONGs/AIDS, são passíveis de todos os logros e dificuldades vivenciados pelas demais organizações. Elas podem prestar um importante trabalho em prol da sociedade, mas também podem se tornar vulneráveis do ponto de vista organizacional e correr o risco de uma atuação indevida ou de se tornarem inoperantes.

É imprescindível, no entanto, que ao existirem, as ONGs preservem a integridade dos valores e propósitos que as originaram, ou seja, a causa, buscando a solidez organizacional que concorre para a transformação social. A AIDS continua sendo um evento promotor de mudanças, o que do ponto de vista das organizações pode se constituir em oportunidade para o aprimoramento enquanto espaços de promoção social.

\section{Colaboradores}

I. M. S. Bochio concebeu e planejou o estudo, levantou os dados, analisou e interpretou os resultados e redigiu o texto. P. A. C. Fortes contribuiu no planejamento do estudo, na análise e interpretação dos resultados e na revisão do texto final. 


\section{Referências}

1. Camara C, Lima RM. Direitos humanos, cidadania e AIDS. São Paulo: Associação Brasileira de Organizações Não Governamentais; 2000. (Cadernos Abong, 28).

2. Falcão J. Democracia, direito e terceiro setor. Rio de Janeiro: Editora FGV; 2004.

3. Galvão J. AIDS e ativismo: o surgimento e a construção de novas formas de solidariedade. In: Parker R, organizador. AIDS no Brasil: história social da AIDS. Rio de Janeiro: Editora Relume-Dumará; 1994. p. 341-50.

4. Bastos FI, Szwarcwald CL. AIDS e pauperização: principais conceitos e evidências empíricas. Cad Saúde Pública 2000;16 Suppl 1:S65-76.

5. Zioni F. Exclusão social: noção ou conceito? Saúde Soc 2006; 15:15-29.

6. Silva CLC. ONGs/AIDS, intervenções sociais e novos laços de solidariedade social. Cad Saúde Pública 1998; 14 Suppl 2:S129-39.

7. Oliveira WF, Junqueira LAP. Questões estratégicas na reforma sanitária: o desenvolvimento do terceiro setor. Rev Admin Pública 2003; 37:227-41.

8. Lopes JR. Terceiro setor: a organização das políticas sociais e a nova esfera pública. São Paulo Perspect 2004; 18:57-66.

9. Rifkin J. Identidade e natureza do terceiro setor. In: Ioschpe EB, organizador. 3 o setor: desenvolvimento social sustentado. Rio de Janeiro: Editora Paz e Terra; 1997. p. 13-23.

10. Junqueira LAP. A gestão intersetorial das políticas sociais e o terceiro setor. Saúde Soc 2004; 13:2536.

11. Souto MC. Projeto AIDS II e a implementação das ações de prevenção do HIV/AIDS no Estado do Rio de Janeiro [Dissertação de Mestrado]. Rio de Janeiro: Escola Nacional de Saúde Pública, Fundação Oswaldo Cruz; 2003.

12. Merege LC, Barbosa MN. 3 o setor: reflexões sobre o marco legal. Rio de Janeiro: Editora FGV; 1998.

13. Marcovitch J. Da exclusão à coesão social: profissionalização do terceiro setor. In: Ioschpe EB, organizador. 3o setor: desenvolvimento social sustentado. Rio de Janeiro: Editora Paz e Terra; 1997. p. 121-30.

14. Salvatore V. A racionalidade do terceiro setor. In: Voltolini R, organizador. Terceiro setor: planejamento e gestão. São Paulo: Serviço Nacional de Aprendizagem Comercial; 2004. p. 17-34.

15. Guilhem D. Escravas do risco: bioética, mulheres e AIDS [Tese de Doutorado]. Brasília: Programa de Pós-graduação em Ciências da Saúde, Universidade de Brasília; 2000.

16. Parker R, Camargo Jr. KR. Pobreza e HIV/AIDS: aspectos antropológicos e sociológicos. Cad Saúde Pública 2000; 16 Suppl 1: 89-102.

17. Fonseca MGP, Bastos FI. Twenty-five years of the AIDS epidemic in Brazil: principal epidemiological findings, 1980-2005. Cad Saúde Pública 2007; 23 Suppl 3:S333-44.

18. Chiavenato I. Introdução à teoria geral da administração. Rio de Janeiro: Campus; 2000.
19. Organización Panamericana de la Salud/Fundación Kellog. Tendencias contemporáneas en la gestión de la salud: concepto sobre programación en los sistemas locales de salud. Washington DC: Organización Panamericana de la Salud; 1996. (Serie HSP-UNI/Manuales Operativos Paltex).

20. Yin RK. Estudo de caso, planejamento e métodos. Porto Alegre: Bookman; 2005.

21. Conselho Nacional de Saúde. Resolução nº. 196, de 10 de outubro de 1996. Dispõe sobre diretrizes e normas regulamentadoras de pesquisas envolvendo seres humanos. Bioética 1996; 4 Suppl 2:15-25.

22. Ferreira AA, Reis ACF, Pereira MI. Gestão empresarial: de Taylor aos nossos dias. São Paulo: Guazzelli; 2000.

23. Cavalheiro TR. O saber epidemiológico nas organizações não governamentais/AIDS exclusivas do Município de São Paulo [Dissertação de Mestrado]. São Paulo: Faculdade de Saúde Pública, Universidade de São Paulo; 1999.

24. Bochio IMS. Marcos de desenvolvimento organizacional da ONG/AIDS - Casa de Assistência Filadélfia - CAF [Dissertação de Mestrado]. São Paulo: Faculdade de Saúde Pública, Universidade de São Paulo; 2005.

25. Fernandes RC. O que é o terceiro setor? In: Ioschpe EB, organizador. 3o setor: desenvolvimento social sustentado. São Paulo: Editora Paz e Terra; 1997. p. 25-33.

26. Fernandes RC. Privado, porém público: o terceiro setor na América Latina. 2a Ed. Rio de Janeiro: Civicus; 1994.

27. Salamon L. Estratégias para o fortalecimento do terceiro setor. In: Ioschpe EB, organizador. 3 o setor: desenvolvimento social sustentado. Rio de Janeiro: Editora Paz e Terra; 1997. p. 89-111.

28. Salada MLA, Marques AS. Vinte anos de assistência a pessoas vivendo com HIV/AIDS no Brasil: a perspectiva de profissionais da saúde. Cad Saúde Pública 2006; 22:2369-78.

29. Figueira SMA. Entre o corpo e a alma: as relações do campo sanitário com o campo religioso [Tese de Doutorado]. São Paulo: Faculdade de Saúde Pública, Universidade de São Paulo; 2003.

30. Tenório FG, organizador. Gestão de ONGS: principais funções gerenciais. Rio de Janeiro: Editora FGV; 2000.

31. Oliveira LA, Landroni MA, Silva NEK, Ayres JRCM. Humanização e cuidado: a experiência da equipe de um serviço de DST/AIDS no Município de São Paulo. Ciênc Saúde Coletiva 2005; 10:689-98.

32. Gohn MG. O protagonismo da sociedade civil: movimentos sociais, ONGS e redes solidárias. São Paulo: Cortez Editora; 2005.

33. Klinksberg B. Seis teses não-convencionais sobre participação. Rev Admin Pública 1999; 33:7-37.

34. Scornavacca JRE, Becker JL, Caravantes GR. Administrando projetos sociais. Rev Adm Pública 1998; 32:159-77.

35. Gohn MG. Empoderamento e participação da comunidade em políticas sociais. Saúde Soc 2004; 13:20-31.

36. Carter I. Desenvolvendo capacidades de grupos locais. Guia Pilares. Viçosa: Editora Ultimato; 2002. 
37. Hernandez JMC, Caldas MP. Resistência à mudança: uma revisão crítica. Revista de Administração de Empresas 2001; 41:31-45.

38. Passeti E. Vitimização e a nova filantropia: um ensaio sobre acomodações de interesses neoliberais. Mundo Saúde 1997; 21:94-7.

39. Secretaria de Políticas de Saúde, Ministério da Saúde. AIDS e sustentabilidade sobre as ações das organizações da sociedade civil. Brasília: Ministério da Saúde; 2001

40. Kliksberg B. Como reformar o Estado para enfrentar os desafios sociais do terceiro milênio. Rev Admin Pública 2001; 35:119-51.
41. Schindler A, Naigeborin V. Empreendedorismo social e desenvolvimento. In: Voltolini R, organizador. Terceiro setor: planejamento e gestão. São Paulo: Serviço Nacional de Aprendizagem Comercial; 2004. p. 169-92.

42. Freitas ME. Contexto social e imaginário organizacional moderno. Revista de Administração de Empresas 2000; 40:6-15.

43. Wilson RH. Understanding local governance: an international perspective. Revista de Administração de Empresas 2000; 40:51-63.

Recebido em 14/Dez/2007

Versão final reapresentada em 11/Mar/2008

Aprovado em 28/Mar/2008 